\title{
Comparison of bailout and planned rotational atherectomy for severe coronary calcified lesions
}

\author{
Cheng-fu Cao, Yu-liang Ma, Qi Li, Jian Liu, Hong Zhao, Ming-yu Lu and Wei-min Wang ${ }^{*}$ (D)
}

\begin{abstract}
Background: To compare outcomes of bailout and planned rotational atherectomy (RA) in the treatment of severe calcified coronary lesions.

Methods: Data of patients treated with RA from 2017 to 2018 at a single-center registry were retrospectively analyzed. All patients were divided into planned RA and bailout RA groups, data between two groups were compared.

Results: A total of 190 patients were included in this study, 138 patients received planned RA and 52 patients received bailout RA. Baseline clinical characteristics had no significant differences between groups. The number of implanted stents and total stents length were similar. But the number of balloon $(1.6 \pm 0.8$ vs. $2.7 \pm 1.3, P<0.001)$, procedure time ( $83.5 \pm 26.2$ vs. $100.8 \pm 36.4 \mathrm{~min}, P=0.007)$, fluoroscopy volume $(941 \pm 482$ vs. $1227 \pm 872 \mathrm{mGy}, P=$ 0.012 ] and contrast amount ( $237 \pm 62$ vs. $275 \pm 90 \mathrm{ml}, P=0.003$ ) were all lower in planned RA group. Planned RA had a higher procedural success rate $(99.3 \%$ vs. $92.3 \%, P=0.007)$ and a lower complication incidence $(4.3 \%$ vs. $17.3 \%, P=0.009)$. But the primary outcomes at 3 years $(9.2$ and $16.6 \%$, log rank $p=0.24$ ) had no difference between groups.
\end{abstract}

Conclusions: For severe coronary artery calcification, although planned RA did not improved the long term prognosis compared with bailout RA, but it can improve the immediate procedural success rate, reduce the incidence of complications, the procedure time and the volume of contrast.

Keywords: Severe coronary calcified lesions, Planned rotational atherectomy, Bailout rotational atherectomy

\section{Background}

Calcified coronary lesions remain a challenge for percutaneous coronary intervention (PCI). Calcified lesions can lead to stent implantation failure or incomplete stent expansion, thus affecting the longterm efficacy of stents. It also increases the risk of perforation and coronary dissection during procedure $[1,2]$. Rotational atherectomy RA plays a key role in the therapy of severe calcified lesions [3, 4]. Although routine RA does not improve the clinical outcomes in

\footnotetext{
*Correspondence: weiminwang@vip.sina.com

Department of Cardiology, Peking University People's Hospital, Beijing, China
}

the ROTAXUS trial, it can significantly improve the success rate of procedure [5]. However, it should be noted that more than $50 \%$ patients in ROTAXUS study were only moderately calcified lesions shown by coronary angiography, and $12.5 \%$ of the patients in the conventional balloon pre-expansion group needed to cross over to RA because of balloon failure of devices. Therefore, it is of great clinical significance to explore when to start RA therapy for severe coronary artery calcification. In the Rotate multicenter registry planned RA appears to be safe and was associated with a reduction in procedural and fluoroscopy times,

(c) The Author(s). 2020 Open Access This article is licensed under a Creative Commons Attribution 4.0 International License, which permits use, sharing, adaptation, distribution and reproduction in any medium or format, as long as you give appropriate credit to the original author(s) and the source, provide a link to the Creative Commons licence, and indicate if changes were made. The images or other third party material in this article are included in the article's Creative Commons licence, unless indicated otherwise in a credit line to the material. If material is not included in the article's Creative Commons licence and your intended use is not permitted by statutory regulation or exceeds the permitted use, you will need to obtain permission directly from the copyright holder. To view a copy of this licence, visit http://creativecommons.org/licenses/by/4.0/. The Creative Commons Public Domain Dedication waiver (http://creativecommons.org/publicdomain/zero/1.0/) applies to the data made available in this article, unless otherwise stated in a credit line to the data. 
contrast volume, and the number of pre-dilation balloon catheters used [6].

The aim of this study was to investigate in a single high volume PCI center the safety and procedural feasibility of a planned RA strategy for the treatment of severely calcified coronary lesions in comparison to a bailout RA approach following device failure.

\section{Methods}

\section{Study design and population}

This is a retrospective single-center study of all patients who underwent PCI using RA because of heavily calcified lesions at our hospital from January 2017 to December 2018. Severely calcified lesion was defined as: radiopacities noted without cardiac motion before contrast injection, generally compromising both sides of the arterial lumen. All the patients were divided into 2 groups according to the indication for RA. Planned RA was defined as initial strategy without previous device failure. Bailout RA was defined as RA after incomplete expansion of balloon or failure delivery of any devices. Pre-intervention intravascular ultrasound (IVUS) or optical coherence tomography (OCT) was performed in partial patients, the patients will receive planned RA if the IVUS/OCT showed calcium angle $>270^{\circ}$ and calcium length $>5 \mathrm{~mm}$ (Fig. 1) or the IVUS/OCT catheter cannot cross the lesions. When discharge from hospital, all the patients were received standard pharmacological treatment (double antiplatelet therapy at least 1 year), and followed-up regularly in clinic.

\section{Data collection}

The demographic and clinical characteristics of all patients included age, gender, medical history, left ventricular function on admission, lipid profiles, serum creatinine, hemoglobin and procedual costs. The angiographic and procedural characteristics included number of diseased vessels, target vessel, the size of burr, total number of stents and total length of stents.

The primary outcome (all-cause death, target vessel revascularization and stent thrombosis) at 3 years were collected during follow-up by telephone or electronic record system.

\section{Procedural details}

Before procedural, all patients received an oral loading dose of $300 \mathrm{mg}$ aspirin and $300 \mathrm{mg}$ clopidogrel. During procedural, all patients received unfractionated heparin at a dose of $70-100 \mathrm{U} / \mathrm{kg}$ to maintain an activated clotting time $(\mathrm{ACT})>300 \mathrm{~s}$. In both groups, the choice of vascular access, burr size, IVUS/OCT was left at the operators' discretion. The IVUS/OCT catheter was advanced beyond the target lesion using a commercially available IVUS/ OCT system (40 MHz IVUS catheter; OptiCross, Boston Scientific. ILUMIEN C7-XR, Abbott). RA was performed by using the Rotablator (Boston Scientific Scimed, Inc., Maple Grove, MN, USA). The burr size was selected to reach a burr/vessel ratio of $0.5-0.6$. RA speed ranged between 150,000 and 180,000 rotation per minute. Each RA time was $10-15 \mathrm{~s}$. During RA, A continuous intracoronary infusion of a cocktail with unfractionated heparin and nitroglycerin was employed. Success of RA was defined as complete expansion of balloon of target lesion after RA.

\section{Study endpoints and definitions}

Procedural success was defined as a final residual stenosis $<30 \%$ after stents and grade 3 TIMI flow. Procedural outcomes included total number of balloon and stents used, procedure time, fluoroscopy amount, and volume of contrast used in the two groups. Procedure time was defined as the interval from initial angiography by

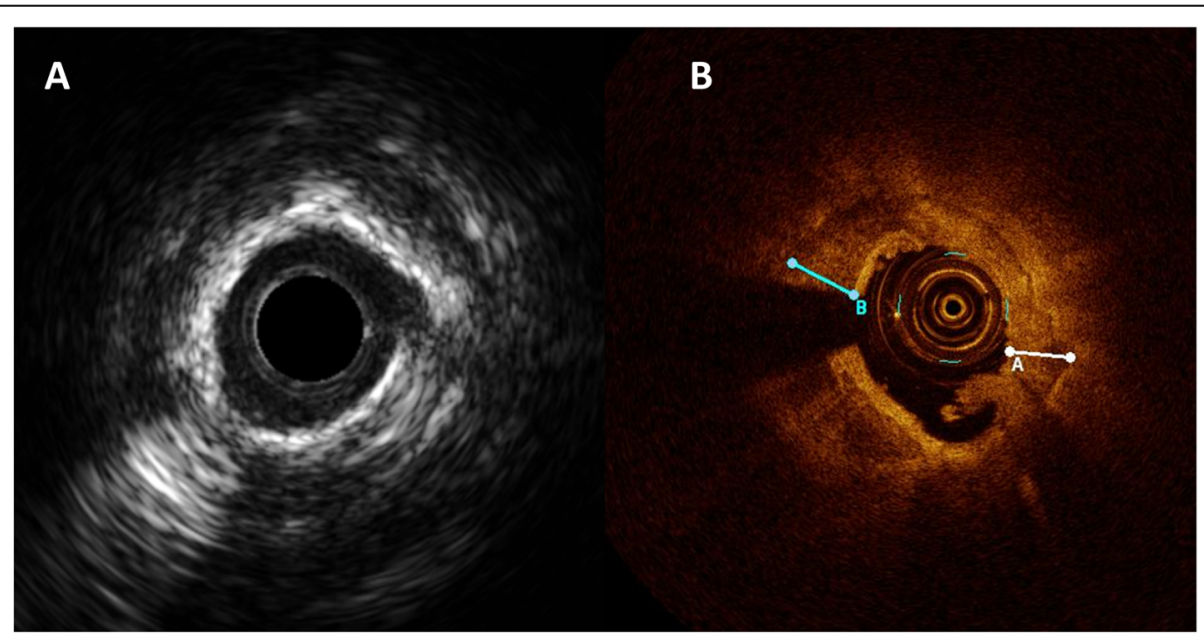

Fig. 1 A representative calcification lesion images of IVUS/OCT. a Shows $360^{\circ}$ calcium with a minimum lumen area $2.1 \mathrm{~mm}^{2}$. b Shows $360^{\circ}$ calcium with maximum calcium thickness $0.58 \mathrm{~mm}$ and minimum lumen area1.8 $\mathrm{mm}^{2}$ 
guiding catheter to final angiography of the target lesion. PCI-related myocardial infarction is defined following the third universal definition of myocardial infarction. Procedure complications included bradycardia, slow-noreflow, dissection, burr entrapment and perforation. Bradycardia was defined as heart rate less than 45 beats per minute which can influence hemodynamics. Dissection was defined as grades $\mathrm{C}$ to $\mathrm{F}$ according to National, Heart, Lung, and Blood Institute (NHLBI) criteria [7]. The primary outcome was a composite of all-cause death, target vessel revascularization and stent thrombosis at 3 years.

\section{Statistical analysis}

Statistical analysis was performed using SPSS for Windows 18.0 (SPSS, Chicago, IL). Continuous variables areexpressed as mean $\pm \mathrm{SD}$, categorical variables are given as frequencies (\%). Univariate comparisons between the two groups were performed using Pearson's chi-square test for categorical variables, and a Student $t$ test for continuous variables. Kaplan-meier was used to analyze the cumulative incidence of clinical events during the follow-up. Difference was considered to be statistically significant at $P<0.05$.

\section{Results}

\section{Patients characteristics}

From January 2017 to December 2018, a total of 190 patients were treated with RA. In 138 patients, RA was performed as a planned procedure, while in other 52 patients, RA was as a bailout procedure. In both groups, patients were old, had a higher proportion of hypertension, Diabetes Mellitus (DM), smoking. Most patients presented as stable coronary artery disease and multivessel disease. Baseline clinical characteristics had no significant differences between both groups. But the proportion of IVUS/OCT guided PCI was higher in planned RA group than that in bailout RA group (Table 1).

\section{Lesion and procedural characteristics}

The most common RA-target vessel was left anterior descending artery in both groups (58.4 and 59.2\% respectively). The most commonly employed burr size was 1.25 $\mathrm{mm}(41.6 \%)$ and $1.5 \mathrm{~mm}(54.2 \%)$. And the use of more than 1 burr was necessary in $5.3 \%$ of all cases. The number of stents and the total stents length had no significant differences between both groups, but the number of balloons in bailout RA group was more than that in planned RA group. In addition, the procedure time, fluoroscopy volume and contrast amount were all lower in planned RA group than bailout RA group (Table 2).

\section{Procedural complication characteristics}

The procedural success was achieved in the majority of cases $(97.4 \%)$, but was lower in the bailout RA group $(92.3 \%$ vs. $99.3 \%, P=0.007)$. There was no coronary perforation in the two groups. The incidence of complications was higher in bailout RA group (17.3\% vs. $4.3 \%)$. The most common complications were bradycardia, slow-no-reflow and dissection (Table 3).

Table 1 Baseline Clinical Characteristics of the Study Population

\begin{tabular}{|c|c|c|c|}
\hline & Planned RA $(n=138)$ & Bailout RA $(n=52)$ & $P$ Value \\
\hline Age (years) & $70.2 \pm 8.3$ & $69.3 \pm 10.1$ & 0.224 \\
\hline Male (\%) & $86(62.3 \%)$ & $36(69.2 \%)$ & 0.376 \\
\hline BMI $\left(\mathrm{kg} / \mathrm{m}^{2}\right)$ & $25.0 \pm 3.0$ & $24.7 \pm 2.6$ & 0.352 \\
\hline Hypertension (\%) & $111(83.3 \%)$ & $38(73.1 \%)$ & 0.272 \\
\hline DM (\%) & $71(51.4 \%)$ & $22(42.3 \%)$ & 0.261 \\
\hline Dyslipidemia (\%) & $35(25.3 \%)$ & $18(34.6 \%)$ & 0.205 \\
\hline Smoking (\%) & $60(43.5 \%)$ & $26(50.0 \%)$ & 0.421 \\
\hline LVEF (\%) & $65.1 \pm 8.2$ & $63.4 \pm 9.4$ & 0.289 \\
\hline Prior PCl (\%) & $30(21.7 \%)$ & $12(23.1 \%)$ & 0.843 \\
\hline Prior CABG (\%) & $3(2.2 \%)$ & $2(3.8 \%)$ & 0.521 \\
\hline $\mathrm{eGFR}<60 \mathrm{ml} / \mathrm{min} / 1.73 \mathrm{~m}^{2}(\%)$ & $16(11.6 \%)$ & $9(17.3 \%)$ & 0.299 \\
\hline Clinical presentation & & & 0.812 \\
\hline SCAD & $31(22.5 \%)$ & $11(21.2 \%)$ & \\
\hline ACS & $107(77.5 \%)$ & $41(78.8 \%)$ & \\
\hline MVD (\%) & $103(74.6 \%)$ & $41(78.8 \%)$ & 0.740 \\
\hline IVUS/OCT-guided (\%) & $35(25.4 \%)$ & $6(11.5 \%)$ & 0.039 \\
\hline
\end{tabular}

BMI Body mass index, DM Diabetes mellitus, LVEF LV ejection fraction, SCAD Stable coronary artery disease, ACS Acute coronary syndrome, MVD Multi-vessel coronary disease 
Table 2 Angiographic and Procedural Characteristics

\begin{tabular}{|c|c|c|c|}
\hline & Planned RA(n=138) & Bailout RA $(n=52)$ & $P$ Value \\
\hline Target vessel & & & 0.031 \\
\hline LM & 2 & 1 & \\
\hline LAD & 111 & 31 & \\
\hline LCX & 4 & 3 & \\
\hline RCA & 21 & 17 & \\
\hline Chronic total occlusion (\%) & $5(3.6 \%)$ & $4(7.7 \%)$ & 0.135 \\
\hline ACC/AHA type B2/C (\%) & $110(79.7 \%)$ & $43(82.7 \%)$ & 0.569 \\
\hline Predilatation (\%) & $136(98.6 \%)$ & $50(96.2 \%)$ & 0.897 \\
\hline Burr size & & & 0.678 \\
\hline 1.25 & 59 & 20 & \\
\hline 1.5 & 73 & 30 & \\
\hline 1.75 & 6 & 2 & \\
\hline More than 1 burr & $7(5.1 \%)$ & $3(5.8 \%)$ & 0.848 \\
\hline Number of balloons & $1.6 \pm 0.8$ & $2.7 \pm 1.3$ & $<0.001$ \\
\hline Number of stents & $2.0 \pm 0.8$ & $2.2 \pm 0.8$ & 0.224 \\
\hline Total stents length (mm) & $60.7 \pm 24.1$ & $62.1 \pm 26.0$ & 0.307 \\
\hline Postdilation(\%) & $137(99.3 \%)$ & $50(96.2 \%)$ & 0.923 \\
\hline Procedure time (min) & $83.5 \pm 26.2$ & $100.8 \pm 36.4$ & 0.007 \\
\hline Procedure cost (Yuan) & $85,090 \pm 22,171$ & $93,801 \pm 25,923$ & 0.342 \\
\hline Fluoroscopy Volume (mGy) & $941 \pm 482$ & $1227 \pm 872$ & 0.012 \\
\hline Contrast amount (ml) & $237 \pm 62$ & $275 \pm 90$ & 0.003 \\
\hline
\end{tabular}

LM Left main, $L A D$ Left anterior descending artery, $L C X$ Left circumflex artery, $R C A$ Right coronary artery

\section{Long time outcomes}

All patients were followed up for a long period, with a median follow-up time of 36 months (1-84 months). At 3 years, the primary outcomes (a composite of all-cause death, target vessel revascularization and stent thrombosis) had occurred in $9.2 \%$ in the planned RA group and $16.6 \%$ in the bailout RA group (log rank p 0.24), and the cumulative 3-year incidences of all-cause death were 6.4 and $12.0 \%$ (log rank p 0.34), the 3-year cumulative rates of target vessel revascularization were 3.0 and 5.1\% (log rank p 0.49), and the 3-year cumulative rates of stent thrombosis were 0.9 and $2.9 \%$ (log rank p 0.46) in planed RA and bailout out RA group respectively. There

Table 3 Complications between groups

\begin{tabular}{llll}
\hline & Planned RA $(\mathrm{n}=138)$ & Bailout RA $(\mathrm{n}=52)$ & $P$ Value \\
\hline Procedural Success & $137(99.3 \%)$ & $48(92.3 \%)$ & 0.007 \\
PCl-related Ml & $7(5.1 \%)$ & $4(7.7 \%)$ & 0.688 \\
Complications & $6(4.3 \%)$ & $9(17.3 \%)$ & 0.009 \\
Bradycardia & 2 & 4 & \\
slow-no-reflow & 2 & 1 & \\
Dissection & 2 & 3 & \\
Burr entrapment & 0 & 1 & \\
\hline
\end{tabular}

was no significant difference between groups $(p>0.05)$ (Fig. 2).

\section{Discussion}

The low success rate and high incidence of complications of severe calcification lesions have always been the difficulty during PCI. RA can significantly improve the success rate. Studies showed that the success rate of RA was $95-96.4 \%[8,9]$. In our study, the success rate of RA was $97.4 \%$. Especially, the success rate in planned RA group was $99.3 \%$, which was significantly higher than that in bailout RA group (92.3\%), suggests that planned RA can significantly improve the success rate for severe coronary artery calcification. There were no differences of long term prognosis between groups.

The complications during RA cannot be ignored. Previous studies [10-12] have shown that common complications and the incidence during RA were coronary dissection (10.5\%), severe coronary spasm (1.6-6.6\%), acute vascular occlusion (3.1\%), slow-no-reflow (1.2$7.6 \%)$ and coronary artery perforation $(0-2 \%)$. The most common complications in our study were bradycardia (3.2\%), coronary dissection (2.6\%), slow-no-reflow (1.6\%) and burr entrapment $(0.5 \%)$. The incidence of complication is high in bailout RA group than that in planned 

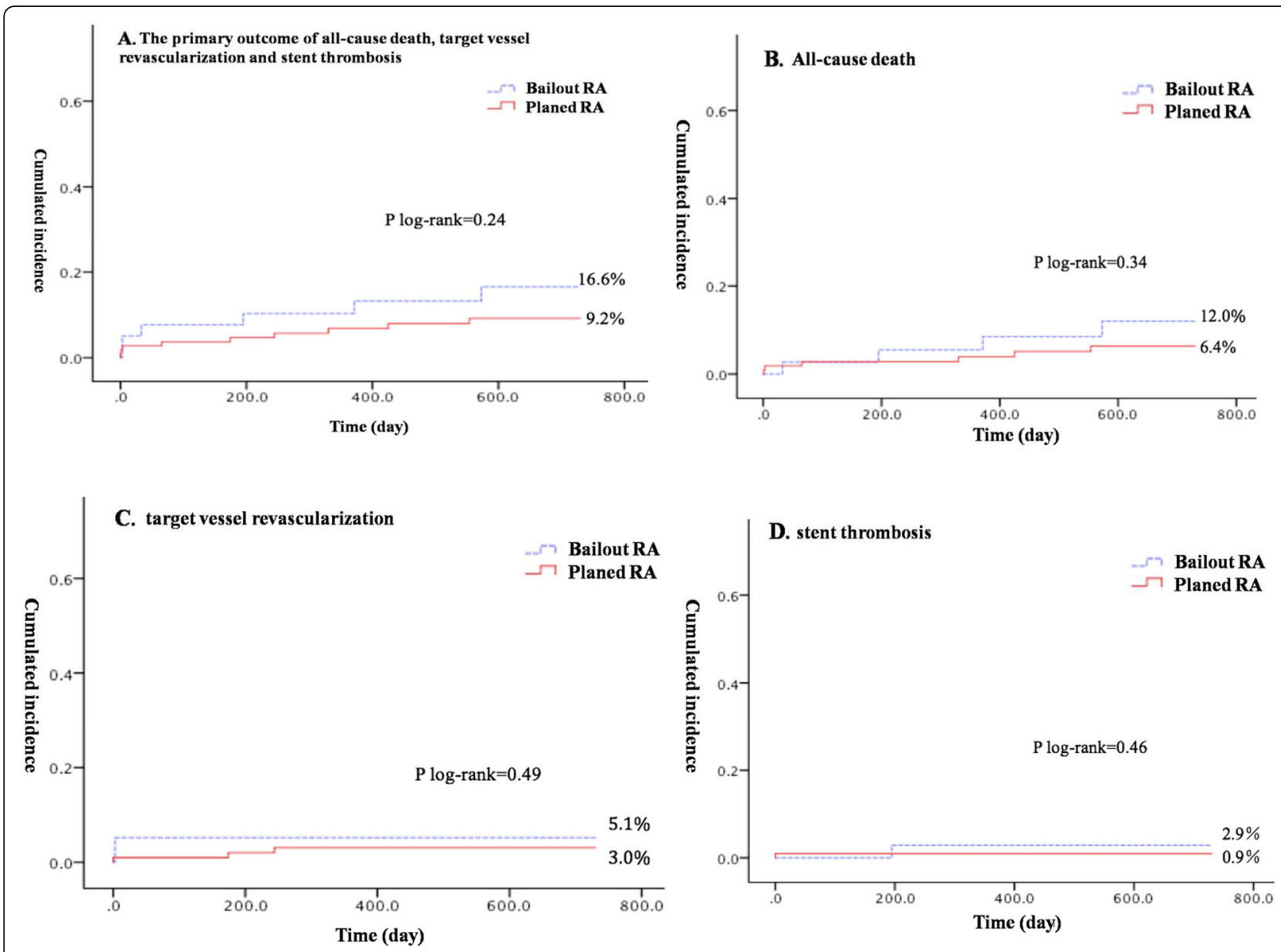

Fig. 2 The primary outcomes between groups

RA group (17.3\% vs. $4.3 \%)$, which shows that planned RA is more safe than bailout RA.

RA is a complicated and time-consuming procedure in the treatment of severe calcified lesions, which may lead to the increase of procedure cost, contrast volume, procedure time and fluoroscopy amount, and thus increase the economic burden of patients and the risk of contrast-induced nephropathy after procedure. However, there are few studies on this issue. Our study showed that compared with bailout RA, planned RA could significantly reduce the procedure time, the volume of contrast used and the fluoroscopy volume during the procedure, which is important for both the interventional cardiologist and the patients. It is consistent with the results of ALLALI et al. [13]. The ROTATE study showed that compared with bailout RA, planned RA did not reduce the adjusted 1year MACE [6]. The results of ALLALI showed that although planned RA could improve the success rate of the procedure, but the incidence of 2-years MACE did not decrease compared with bailout RA (25.2\% vs $28.7 \%, \log \operatorname{rank} P=0.52$ ) [13].
The major limitation of this study is its non randomized design in which operator bias and unmeasured confounders may prohibit definitive conclusions. Limited number of patients, especially in bailout RA group, and not randomized retrospective study design could bias the outcomes.

\section{Conclusions}

Overall, our study showed that, for severe coronary artery calcification, although planned RA did not improve the long term prognosis than bailout RA, but it can improve the immediate procedural success rate, reduce the incidence of complications, the procedure time and the volume of contrast compared with bailout RA.

\section{Abbreviations}

PCl: Percutaneous coronary interventions; RA: Rotational atherectomy; IVUS: Intravascular ultrasound; OCT: Optical coherence tomography;

ACT: Activated clotting time; DM: Diabetes mellitus

\section{Acknowledgements} Not applicable. 


\section{Authors' contributions}

CAO CF and LI Q were major contributors in writing the manuscript. MA YL analyzed and interpreted the patient data, LIU J, ZHAO H and LU MY collected patients data, WANG WM was the corresponding author. The authors read and approved the final manuscript.

\section{Funding}

This study was supported by The National Natural Science Foundation of China (No. 81800316). These funds designed the study, collection and analysis of the data.

\section{Availability of data and materials}

The datasets used during the current study are available from the corresponding author on reasonable request.

\section{Ethics approval and consent to participate}

This study was approved by the ethics at Peking University People's Hospital, all patients provided written informed consent before participation.

\section{Consent for publication}

Not applicable.

\section{Competing interests}

The authors declare that they have no competing interests.

Received: 22 March 2020 Accepted: 31 July 2020

Published online: 15 August 2020

\section{References}

1. Tran T, Brown M, Lasala J. An evidence-based approach to the use of rotational and directional coronary atherectomy in the era of drugeluting stents: when does it make sense? Catheter Cardiovasc Interv. 2008;72:650-62.

2. Kuriyama N, Kobayashi Y, Yamaguchi M, Shibata Y. Usefulness of rotational atherectomy in preventing polymer damage of everolimus-eluting stent in calcified coronary artery. JACC Cardiovasc Interv. 2011;4:588-9.

3. Hodgson J, Stone G, Lincoff AM, Klein L, Walpole H, Bottner R, et al. Late stent thrombosis: considerations and practical advice for the use of drugeluting stents: a report from the Society for Cardiovascular Angiography and Interventions Drug-Eluting Stent Task Force. Catheter Cardiovasc Interv. 2007;69:327-33.

4. Barbato E, Carri D, Dardas P, Fajadet J, Gaul G, Haudeet M, et al. European expert consensus on rotational atherectomy. Eurolntervention. 2015;11:30-6.

5. Abdel-Wahab M, Richardt G, Joachim Büttner H, Toelg R, Geist V, Meinertz $T$, et al. High-speed rotational Atherectomy before paclitaxeleluting stent implantation in complex calcified coronary lesions: the randomized ROTAXUS (rotational Atherectomy prior to Taxus stent treatment for complex native coronary artery disease) trial. JACC Cardiovasc Interv. 2013;6:10-9.

6. Kawamoto H, Latib A, Ruparelia N, Boccuzzi GG, Pennacchi M, Sardella G Planned versus provisional rotational atherectomy for severe calcified coronary lesions: insights from the ROTATE multi-center registry. Catheter Cardiovasc Interv. 2016;88:881-9.

7. Huber MS, Mooney JF, Madison J, Mooney MR. Use of a morphologic classification to predict clinical outcome after dissection from coronary angioplasty. Am J Cardiol. 1991;68:467-71.

8. Furuichi S, Sangiorgi GM, Godino C, Airoldi F, Montorfano M, Chieffoet A, et al. Rotational atherectomy followed by drug-eluting stent implantation in calcified coronary lesions. Eurolntervention. 2009;5:370-4.

9. Schwartz BG, Mayeda GS, Economides C, Kloner RA, Shavelle DM, Burstein S. Rotational atherectomy in the drug-eluting stent era: a single-center experience. J Invasive Cardiol. 2011;23:133-9.

10. Warth DC, Leon MB, O'Neill W, Zacca N, Polissar NL, Buchbinder M. Rotational atherectomy multicenter registry: acute results, complications and 6-month angiographic follow-up in 709 patients. J Am Coll Cardiol. 1994;24:641-8.

11. Benezet J, de la Llera LSD, Cubero JM, Villa M, Fernández-Quero M, SánchezGonzález A. Drug-eluting stents following rotational atherectomy for heavily calcified coronary lesions: long-term clinical outcomes. J Invasive Cardiol. 2011;23:28-32
12. Dardas P, Mezilis N, Ninios V, Tsikaderis D, Theofilogiannakos EK, Lampropoulos $\mathrm{S}$. The use of rotational atherectomy and drug-eluting stents in the treatment of heavily calcified coronary lesions. Hellenic J Cardiol. 2011:52:399-406.

13. Allali A, Abdel-Wahab M, Sulimov DS, Jose J, Geist V, Kassner G. Comparison of bailout and planned rotational Atherectomy for heavily calcified coronary lesions: a single-center experience. J Interv Cardiol. 2017;30:124-33.

\section{Publisher's Note}

Springer Nature remains neutral with regard to jurisdictional claims in published maps and institutional affiliations.
Ready to submit your research? Choose BMC and benefit from:

- fast, convenient online submission

- thorough peer review by experienced researchers in your field

- rapid publication on acceptance

- support for research data, including large and complex data types

- gold Open Access which fosters wider collaboration and increased citations

- maximum visibility for your research: over $100 \mathrm{M}$ website views per year

At $\mathrm{BMC}$, research is always in progress.

Learn more biomedcentral.com/submissions 